\title{
Prevalence and Measurement of Anxiety and Depression in Nurses During Covid Pandemic in Nepal
}

\section{Pramila Karki}

Vatsalya IVF Center

George B. J. Katwal

Annapurna Neurological Institute and Allied Sciences

Ayush Chandra

Tianjin Medical University

Avinash Chandra ( $\nabla$ chandraavi@gmail.com )

KIST Medical College https://orcid.org/0000-0002-3895-5369

\section{Research}

Keywords: Anxiety, Depression, Nurse, Mental Health, COVID, Pandemic

Posted Date: June 17th, 2020

DOI: https://doi.org/10.21203/rs.3.rs-34462/v1

License: (a) (i) This work is licensed under a Creative Commons Attribution 4.0 International License. Read Full License 


\section{Abstract}

\section{Background}

Anxiety and depression are under reported, underdiagnosed mental illness inhealth worker in Nepal especially during COVID pandemic. The study was carried out as an observational studyon nurses in Nepal. In this study we attempted to assess the incidence and impact of depression and anxietyin nurses who are working upfront in different hospitals during this crisis.

\section{Objective}

The purpose of the study is to assess the prevalence of anxiety and depression among nurses in Nepal during COVID pandemic who are working in various hospitals.

\section{Method}

A cross-sectional non-probability purposive sampling with observational analysis was carried out and the sample was collected from nurses working in different hospitals. Prevalence of anxiety and depression was assessed using a structured and validated questionnaire. Anxiety was assessed with theHamilton Anxiety Scale (HAM-A), General Anxiety Disorder Questionnaires (GAD) with a cut-off score for various levels of anxiety while Hamilton Depression Rating Scale (HAM-D)was used to assess depression.

\section{Result}

The analysis of these different scales revealed that disabling anxiety prevailed at highest $(43.6 \%)$ in nursing staff according to HAM-A scale. Moderateanxiety also seemed to be higher $(>20 \%)$ in GAD questionnaire.

\section{Conclusion}

This is the first study carried out in Nepal that investigates the mental health of nurses who are working in the frontline in this COVID pandemic situation. The study revealed that our nurses who have given their life in the line are suffering from serious mental health problems.

\section{Introduction}

The unprecedented effect of COVID pandemic has shattered the health system globally and the worst effect has been observed in already fragile healthcare system in low- or middle-income nations (LMICS) like Nepal. The fear of contagion, stigmatization of COVID, social isolation and the compulsion of performing duty despite the adverse environment to attend patients has undeniably brought lots of stress and other mental health disorders in healthcare workers worldwide. (1) Anxiety and depression are one of the most common mental health issues that we suffer. Several research reports on the prevalence of depression and anxiety on medical students and nursing students. (2) The nursing education has come a 
long way in Nepal. It has been not more than the five decades since the formal nursing education started in Nepal before which there was no single health institution involved in nursing or other medical education. (3) The education system caught its pace and today nursing education system has entered the maturity in Nepal. In Nepal, there are various categories of nursing education and the degrees are awarded accordingly. Among various categories, there are two formal nursing degrees.

1. 1. The proficiency certificate level in nursing (PCL) or staff nurse which was started in 1999. PCL nursing is one of the prominent and popular disciplines within the Nursing profession. It is taught for 3 years and is accepted to the equivalence to the diploma in nursing internationally. The curriculum is designed with the purpose of producing middle level technical nursing workforce equipped with knowledge and skills related to the field of nursing to meet the demand of such workforce in the country to contribute in the national economic and health development of Nepal. In total three years; the first-year course is focused on basic nursing care in hospital and in the community: foundation nursing practices; the second-year course is focused on preventive, promotive as well as therapeutic nursing care of sick adult and elderly individual as well as mentally ill individual. Similarly, the thirdyear course comprise of the pediatric, midwifery and gynecology as well as leadership and management.

2. 2. The other popular nursing course is a four-year course and awarded as Bachelor of science in nursing (B.Sc. Nursing). This program aims to prepare professional nurse with the highest possible technical and managerial competence in the level of health programs, including problem identification, planning, implementing, training, health education, evaluation, and research. This program is accepted equivalent to international BSc Nursing.

The low salary and excessive workload are the major issue in Nepal's nursing profession, and no incentive even during the COVID pandemic while they are working at the frontlines. The average salary of a junior nurse is around $\$ 100$ a month. With the bachelor's degree, the pay could rise as high as $\$ 200$, which is still a meagre amount in comparison to the developed nations. To get a nursing education, the expenditure on average involves paying $\$ 3000$ for PCL and $\$ 12000$ or more for B.Sc. Nursing (according to the admission section of a parent University).

Demand of nurses is another major issue in the country. The nurse to patient ratio should be proportional to the workload and nurses' specialization. (3)This ratio is very low in Nepal. Usually 20-30 occupant (patients) in a unit is covered by only 1-2 nurses in most hospitals. Usually, they also must carry out nonnursing jobs which are time consuming and distract them from their work. Overload and overwork are one of the challenges facing nurses in Nepal. In addition to that, the increase in COVID infected patients and their visits to the hospital has added to the already exhaustive nursing work.

Anxiety and depression in nurses have been quite dreadful than perceived. Systematic reviews and metaanalyses published have indicated that the prevalence of anxiety and depression among medical students worldwide was as high as $28 \%$, and suicidal ideation was around $11.1 \%$.(4-6) There are not many papers that report on the prevalence of anxiety and depression selectively among nurses that are 
not students or interns but have already graduated and employed in hospitals.(7) Country wise, few papers published on depression symptoms in nurses indicate the prevalence of anxiety symptom from $18-40 \%$ in nurses in United States, $11-80 \%$ in Iranian nurses,(8) $35 \%$ in Chinese nurses(9) while $41.2 \%$ in Australian nurses.(10) A survey done in Vietnam showed that the prevalence of depression and anxiety is higher than the prevalence of anxiety and depression in general population of that country. $(11,12)$ The low socio-economic status, longer working period, uncertainty for the future and low earning than the counterparts working in abroad countries add the fuel to the fire of anxiety and depression.

Finding and addressing the depression in nursing profession should be given the priority as it may significantly impact the quality of care they provide to the consumers. In this study we have attempted to see the prevalence of anxiety and depression among nurses who are working in different hospitals in Nepal. Nurses regularly face a various types of stressors including longer work hours, meeting patient's requirements, and the patient attendant's expectations, besides lack of professional support.(10)The COVID pandemic has affected considerable portion of health care workers' mood, sleep disturbances. (13)The depressed staff often exhibit low or irritable mood, difficulty focusing and as a result are accident prone and lower total work output and decreased efficiency. $(14,15)$ The accurate measurement and identification of depression and anxiety is challenging because of frequent overlapping or cooccurrence of these conditions but it needs to be addressed.

\section{Methods}

1. 2.1 Design: A cross-sectional non-probability purposive sampling with observational analysis in a cohort of Nepalese nurses working in different hospitals in the frontline during COVID pandemic.

2. 2.2 Sample and setting: Nurses who were already employed and working in hospitals as a frontline medical staff for COVID-19 were included in the study. Data were collected using the different set of questionnaires (HAM-A, HAM-D and GAD) were used for the assessment of anxiety and depression. Rationale for the study was that we wanted to see the level of depression in employed nurses. Our assumption was that, the nursing students are more vulnerable to depression as they are surrounded by stressful situations for example, uncertainty of getting infection, uncertainty of materializing dreams as. We were also particular to selecting only those nurses who had no previous anxiety history in them or the family or family relatives. The level of anxiety and depression was based on the scores and their respective cutoff points. HAM-A consisted of mild, moderate, severe, grossly disabling depression, while GAD included as mild, moderate, and severe based on their scores, respectively. HAM-A is a checklist of self-answerable questionnaires that assist in evaluating each participant as to the degree of anxiety in pathological condition. It is one of the first rating scales developed to measure the severity of anxiety symptoms and is still widely used today in both clinical and research settings. HAM-A consists of 14 items, each defined by a series of symptoms. The total score range of 0-56, where less than 17 indicated mild severity, 18-24 mild to moderate severity and 25-30 as moderate to severe. (16) GAD is also another easy to perform initial screening tool for generalized anxiety disorder. We have used GAD questionnaires, also called as GAD 7 consisting of 7 
elements and it is obtained by adding score for each question. The result was grouped according to the score achieved. From score $0-5$ was grouped as mild anxiety, $6-10$ as moderate anxiety, 11-15 as severe anxiety. Using a threshold of 10 , it has shown fair amount of Sensitivity (> 89\%) and Specificity (> 82\%). (17) Anxiety was measured using HAM-A, GAD 7and depression measured with HAM-D scales. HAM-D consisted of 21 questions among which if the participants are diagnosed as from none to severe anxiety according to the score, they get up to the 17th questions. HAM-A consists of 14 sets of questions and the score of $<17$ denotes mild severity while $>25$ denotes severe.

3. 2.3 Data collection and data analysis: Data were collected from 64 clinically active nurses working as a frontliner (front line medical staff) in different hospitals in Nepal. The data were collected in 2 months duration (March-May 2019) and since we were very rigid about the selection and also due to the ongoing crisis, we were not able to collect many participants $(n=64)$. This study was a pilot study and the preliminary results would help us carry further research. Prior to inclusion, all participants were screened for chronic diseases including previously diagnosed clinical depression, or other mental health issues and were excluded from the study if found. The personal history for the exclusion was chronic smoking habits (> 10 cigarettes per day), alcohol intake (more than 16 standard drinks per day). Data were entered and analyzed with SPSS (version 20). The descriptive statistical analysis was run through the data. The frequency was calculated using descriptive analysis and the association between different scales (HAM-A and GAD) and (HAM-D and GAD) was analyzed by using analysis of variance (ANOVA) one way. This study had obtained the institutional review board approval and all participants were well informed in written as well as in oral form. Their names were coded, and all other information were kept secret. The data was entered by one of the authors who was blinded to the participants. Only those participants were included who consented.

\section{Results}

Interestingly, only female pursue the career as a nurse in Nepal and hence our study consisted of only female sex. Hence, we could not show the gender difference in anxiety and depression in our study. The analysis was done. The analysis revealed that highest number of participants $n=34(43.6 \%)$ were suffering from disabling anxiety according to HAM-A scale. Apart from that, $n=16(20.5 \%)$ of participants had mild and $n=7(9 \%)$ had severe anxiety (table 1$)$. None of our participants denied any anxiety. In GAD scoring, the analysis revealed that $n=20$ (25.6\%) of our participants suffered from moderate anxiety, while $n=3(10.3 \%)$ had severe anxiety and $n=13(16.7 \%)$ had mild anxiety (table 2).Like the HAM-A scale, none of our GAD participants denied anxiety. There was a strong correlation between HAM-A and GAD as well as in HAM-D and GAD in our participants which was seen in ANOVA. The association between HAM$D$ and GAD had significant positive correlation $(p=0.016)$, and the association between HAM-A and GAD even showed stronger positive correlation $(p=0.008)$. Among the elements of HAM-D, strong significant $(p=0.00)$ was seen with anxiety (psychological) and anxiety (somatic), hypochondriasis.

\section{Discussion}


There several research papers published on anxiety and depression on general population but not many on working nurses. Among that, very scanty papers talk on depression and anxiety in nurses in low economic countries and that among the frontline health workers.(13) Nepal falls in a low and middleincome countries (LMICS) and the social anxiety disorder is much prevalent in these nations(18), yet only few literatures emphasize on the mental health issues in health workers especially on the nurses who work in hospital. In nurses who have graduated and employed in hospital, are expected to have comparatively lesser anxiety than the student group as they have no more exams or stress to graduate. Contrary to this belief, our study revealed that the anxiety and depression level is very prevalent in the employed nurses. Our finding agrees with the analysis done by Letvak et al, and Mahraj et al, in which they found that the hospital employed nurses have higher rates of depressive and anxiety symptoms.(7, 10) Similar kind of result in our study could be mainly due to the poor working condition, low salary jobs and as a result low satisfaction to the job. The lack of insurance policy by the employer or hospital, insecure future in hospital and fewer number of nurses to large number of patients are some important factors contributing to the stress, dissatisfaction and frustrations of nurses towards their profession and causing anxiety and depression in Nepal. The ratio of patient to nurse is pitiful. Usually 20-30 admitted patients in a department unit is covered by only 1-2 nurses in most hospitals. Nurses are not only concerned with the nursing jobs, but they also must carry out non-nursing jobs which are time consuming and distract them from their work. Overload and overwork are one of the main challenges facing nurses in Nepal. The duty hours are very high (it is usually called double shift duty in Nepal in which nurses work from morning 7AM till 6PM). High number dissatisfaction and higher number of nurses migrating to foreign countries is prevalent in Nepal. Comparatively easier access to the foreign countries like Australia, UK with better working environment and higher salary with comparatively secured job are some main factors attracting nurses. As a result, recent data shows that in Nepal every 1 among 6 nurses successfully get the visa and migrate to other countries working as a nurse (applicants are many more.) On addition to these, highly stressful job, and low number of staff also could be the reason for anxiety and depression. High turnover, absenteeism, and lost productivity within the health workforce could amplify shortages and easily leave facilities understaffed and unable to meet patient demands, placing patients at risk.(19) The low job satisfaction is one of the reasons for the anxiety symptoms among working nurses as found in a study on German nurses.(20)Several researches have shown that poor mental health may led to decrease in cognitive performances and ultimately resulting in inadequate performance.(21)and thus there can be serious consequences to the situation where staff work under extreme anxiety and stress. There are some limitations in our study. A small representative sample and the homogeneity of gender (all females) are the main limitations of the study. Another limitation is that the study is a cross-sectional observational study design, and self-answerable questionnaire were used, which is very subjective and variable in understanding. We also could not perform comparative analysis that we could compare between pre and post pandemic situation. Thus, further research seems inevitable that would include larger sample and different other questionnaires with higher specificity. Homogeneity of gender is hard task to eliminate in Nepal ae the requirement for nursing profession is that they must be female. Nevertheless, our study points out several important aspects of mental health in working nurses that needs to be considered. Further research may benefit from larger sample, and longitudinal type of 
study as well as more elements to be included. A more comprehensive assessment of demographic, personal and work-related factors need to be included as well.

\section{Conclusion}

Nursing is an indispensable part of our health care system. Patient care, hospitalization and other management rely heavily upon their ability to work optimally and without them it would be impossible to deliver the best possible care. Thus, the increasing anxiety depression among nurses cannot be afforded to ignore. The higher prevalence of anxiety depression among nurses as shown through our study is a witness of the fact that the working situation of nurses need to be considered in due time not only during the COVID pandemic. The anxiety among working nurses may not be totally preventable but the recognition of the problem would certainly bring many measures to curb it down. Thus, further bigger research is needed to help care for the well-being of nurses and minimize poor mental health in workplace. This study certainly calls for the policy makers to consider the situation and bring out any short term and long-term support strategies and interventions that would combat the psychological stress and exhaustion and thus improve the mental health of working nurses.

\section{Abbreviations}

HAM-A

The Hamilton Anxiety Scale

GAD

General Anxiety Disorder Questionnaires

HAM-D

Hamilton Depression Rating Scale

IRC

Institutional Review Committee

\section{Declarations}

\section{Ethics approval and consent to participate}

This study was reviewed and approved by the institutional review committee (IRC) of Nepal Health Research Council. It was conducted in accordance with the Declaration of Helsinki. Additionally, all participants who agreed to participate were only enrolled after giving written informed consent.

\section{Availability of data and material}

Data supporting can be obtained from the table provided in the study and the further can be obtained upon the requirement/or request to the corresponding author.

\section{Competing interest}


The authors declare that there is no competing interest

\section{Funding}

The authors received no financial support for the research, authorship or whatsoever related to the publication.

\section{Authors' Contributions}

All authors have made substantial contributions to this manuscript.

PK contributed to the conceptualization and drafted the article. GBJK and AC critically revised the article. AC contributed to the statistical analysis, study design

\section{Acknowledgements}

Not applicable

\section{References}

1. McGinty EE, Presskreischer R, Han H, Barry CL. Psychological Distress and Loneliness Reported by US Adults in 2018 and April 2020. JAMA. 2020.

2. Moir F, Yielder J, Sanson J, Chen Y. Depression in medical students: current insights. Adv Med Educ Pract. 2018;9:323-33.

3. Poudel C, Ramjan L, Everett B, Salamonson Y. Exploring migration intention of nursing students in Nepal: A mixed-methods study. Nurse Educ Pract. 2018 Mar;29:95-102.

4. Puthran R, Zhang MW, Tam WW, Ho RC. Prevalence of depression amongst medical students: a meta-analysis. Med Educ. 2016 Apr;50(4):456-68.

5. Rotenstein LS, Ramos MA, Torre M, Segal JB, Peluso MJ, Guille C, et al. Prevalence of Depression, Depressive Symptoms, and Suicidal Ideation Among Medical Students: A Systematic Review and Meta-Analysis. JAMA. 2016 Dec 6;316(21):2214-36.

6. Tam W, Lo K, Pacheco J. Prevalence of depressive symptoms among medical students: overview of systematic reviews. Med Educ. 2019 Apr;53(4):345-54.

7. Letvak S, Ruhm CJ, McCoy T. Depression in hospital-employed nurses. Clin Nurse Spec. 2012 MayJun;26(3):177-82.

8. Ardekani ZZ, Kakooei H, Ayattollahi SM, Choobineh A, Seraji GN. Prevalence of mental disorders among shift work hospital nurses in Shiraz, Iran. Pak J Biol Sci. 2008 Jun 15;11(12):1605-9.

9. Cheung T, Yip PS. Depression. Anxiety and Symptoms of Stress among Hong Kong Nurses: A Crosssectional Study. Int J Environ Res Public Health. 2015 Sep 7;12(9):11072-100.

10. Maharaj S, Lees T, Lal S. Prevalence and Risk Factors of Depression, Anxiety, and Stress in a Cohort of Australian Nurses. Int J Environ Res Public Health. 2018 Dec 27;16(1). 
11. Nguyen DT, Dedding C, Pham TT, Wright P, Bunders J. Depression, anxiety, and suicidal ideation among Vietnamese secondary school students and proposed solutions: a cross-sectional study. BMC Public Health. 2013 Dec 17;13:1195.

12. Vuong DA, Van Ginneken E, Morris J, Ha ST, Busse R. Mental health in Vietnam: Burden of disease and availability of services. Asian J Psychiatr. 2011 Mar;4(1):65-70.

13. Pappa S, Ntella V, Giannakas T, Giannakoulis VG, Papoutsi E, Katsaounou P. Prevalence of depression, anxiety, and insomnia among healthcare workers during the COVID-19 pandemic: A systematic review and meta-analysis. Brain Behav Immun. 2020 May 8.

14. Schreiber MA, Differding J, Esposito TJ. Research: questions and answers from academic trauma surgeons. J Trauma. 2008 Apr;64(4):1113-7; discussion 7-8.

15. Wang J, Schmitz N, Smailes E, Sareen J, Patten S. Workplace characteristics, depression, and healthrelated presenteeism in a general population sample. J Occup Environ Med. 2010 Aug;52(8):836-42.

16. Matza LS, Morlock R, Sexton C, Malley K, Feltner D. Identifying HAM-A cutoffs for mild, moderate, and severe generalized anxiety disorder. Int J Methods Psychiatr Res. 2010 Dec;19(4):223-32.

17. Plummer F, Manea L, Trepel D, McMillan D. Screening for anxiety disorders with the GAD-7 and GAD2: a systematic review and diagnostic metaanalysis. Gen Hosp Psychiatry. 2016 Mar-Apr;39:24-31.

18. Stein DJ, Lim CCW, Roest AM, de Jonge P, Aguilar-Gaxiola S, Al-Hamzawi A, et al. The cross-national epidemiology of social anxiety disorder: Data from the World Mental Health Survey Initiative. BMC Med. 2017 Jul;31(1):143. 15(.

19. Int J Nurs Pract. 2015 Aug;21(4):359 - 66.

20. Schulz M, Damkroger A, Voltmer E, Lowe B, Driessen M, Ward M, et al. Work-related behaviour and experience pattern in nurses: impact on physical and mental health. J Psychiatr Ment Health Nurs. 2011 Jun;18(5):411-7.

21. Marazziti D, Consoli G, Picchetti M, Carlini M, Faravelli L. Cognitive impairment in major depression. Eur J Pharmacol. 2010 Jan 10;626(1):83-6.

\section{Tables}


Table 1

Frequency chart of anxiety category according to HAMA

\begin{tabular}{|llll|}
\hline Anxiety & & Frequency & Percent \\
\hline HAM-A & Mild Anxiety & 16 & 20.5 \\
\cline { 2 - 4 } & Moderate Anxiety & 5 & 6.4 \\
\cline { 2 - 4 } & Severe Anxiety & 7 & 9.0 \\
\cline { 2 - 4 } & Disabling Anxiety & 34 & 43.6 \\
\hline & & \\
\hline
\end{tabular}

Table 2

Frequency table for type of anxiety for GAD

\begin{tabular}{|lll|}
\hline Anxiety & Frequency & Percent \\
\hline GAD & & \\
\hline Mild & 13 & 16.7 \\
\hline Moderate & 20 & 25.6 \\
\hline Severe & 8 & 10.3 \\
\hline
\end{tabular}

